\title{
Are We Spinning Our Wheels? The Impact of PBIS, Counseling, and Mentoring on the Behavior and Achievement of Elementary Age African American Males
}

\author{
Elesha Buckley ${ }^{1}$, Myron Labat ${ }^{2}$, David Lee ${ }^{3} \&$ Cherie Labat ${ }^{4}$ \\ ${ }^{1}$ Hattiesburg Public School District, Hattiesburg, MS, USA \\ ${ }^{2}$ Educational Leadership, Mississippi State University, Mississippi State, MS, USA \\ ${ }^{3}$ Educational Leadership, University of Southern Mississippi, Hattiesburg, MS, USA \\ ${ }^{4}$ Columbus Municipal School District, Columbus, MS, USA
}

Correspondence: Myron Labat, Educational Leadership, Mississippi State University, 248-D Allen Hall P.O. Box 6037 Mississippi State, MS., 39762 USA. Tel: 1-228-323-4980. E-mail: mbl225@msstate.edu

Received: November 15, 2019

doi:10.5430/irhe.v4n4p7
Accepted: December 9, 2019 Online Published: December 20, 2019

URL: https://doi.org/10.5430/irhe.v4n4p7

\begin{abstract}
The gap in educational achievement between African American males and their peers plays a key role in one of the most substantial problems facing American society (Burchinal, McCartney, Steinberg, Crosnoe, Friedman, McLoyd, \& Picanta, 2011). However, the challenges faced by those working to narrow the achievement gap between African American males and their counterparts continue to persist. The purpose of this study was to explore the impact of Positive Behavior Intervention and Support (PBIS), counseling, and mentoring on disruptive classroom behavior among African American males. The researchers also examined whether Positive Behavior Intervention and Support (PBIS), counseling, and mentoring had an impact on reading scores of African-American male students in Pre-K through fifth grade. Prior studies in this area indicated that participation in PBIS was not a significant predictor of the number of disruptive behaviors that resulted in office referrals received by African American male students in Pre-K through fifth grade. Findings in this study seemed to be consistent with those studies. However, researchers did find participation in counseling to be a significant predictor of disruptive behaviors among African American male students in Pre-K through fifth grade.
\end{abstract}

Keywords: PBIS, school culture, achievement gap, counseling and mentoring, Black males

\section{Introduction}

African American males fall well behind their White male and female peers when it comes to achievement on standardized testing. They also lag behind Black females in their achievement on math and science standardized tests (Praeger, 2011). Black males are also more likely to be labeled as having a learning disability and placed in special education than any other student group (Zilanawala, Martin, Noguera, and Mincy, 2018). Furthermore, nearly half of African American males do not complete high school in most American cities (Praeger, 2011). Bracy and Peguero (2014) assert that those who do not graduate from high school have poorer health, have a greater probability of being unemployed, they are more likely to be delinquent and use drugs, and have a higher likelihood of incarceration. Taking into consideration these potential outcomes, it is understandable why this issue has caught the attention of educators and researchers all across the nation. Praeger (2011) further conceptualizes the severity of this pervasive issue by pointing out that schools are serving populations of Black boys who have a higher probability of being incarcerated than they do entering college.

In addition to the substantial achievement gap between African American males and their counterparts, there also exists a discipline gap (Gregory, Skiba, \& Noguera, 2010). According to Rudd (2014) and Richard and Hardin (2018), Black males are disciplined more often for disruptive behavior and are suspended and expelled more often than White students. More than $70 \%$ of the school children involved in school-associated arrests or referred to law enforcement were Hispanic or African American (Rudd, 2014). The findings of a survey of 72,000 schools revealed that African American students comprised only 18 percent of those enrolled in the schools, yet they accounted for 
$35 \%$ of those suspended one time, $46 \%$ of those suspended more than one time, and $39 \%$ of those expelled (Rudd, 2014). This is a major concern given that student achievement decreases when students are not present in class to receive instruction.

\subsection{Theoretical Framework}

The Albert Bandura's social learning theory served as the theoretical framework for this study. Social learning theory suggested that individuals learn from others through observation, imitation, and modeling (Bandura, 1971). There are three main concepts of Albert Bandura's Social Learning Theory (SLT). Bandura (1969) wrote that people learn through observing others. The second key concept of SLT is that core psychological condition of a person is important to learning. Thirdly, Bandura (1971) posited that learning does not always result in a change in behavior. Bandura (1971) theorized that new patterns of behavior are attainable through observing others. Bandura (1971) expounded on the three basic models of learning through observation. Live models involve actual person demonstrating or carrying out a behavior. Verbal instructional models involve descriptions of a behavior. Bandura $(1969,1977)$ explained that symbolic models involve real and fictional characters displaying behaviors in films, books, and television programs.

Bandura (1977) wrote that a person's psychological state and sense of self were instrumental to the learning process and behavior. Bandura (2001) purported that socio-structural factors, though external, operate through internal psychological mechanisms of the self- system to produce behavioral effects. Bandura (2001) explained that the external factors of educational and family structures, socioeconomic status, and economic conditions affect behavior immensely. Bandura (2001) stated that these factors indirectly affect behavior through the impact on people's ambitions, sense of efficacy, personal values, affective states, and other self-regulatory influences. He maintained that self-regulated incentives affect behavior mainly through their ability to motivate. According to Bandura (1971, 1978), human behavior is largely regulated through intrinsic reinforcement in the form of self-satisfaction, self-pride, self-dissatisfaction, self-criticism, and a sense of accomplishment. He explained people motivate themselves to exert the effort needed to attain the desired goals when people make self-satisfaction or tangible accomplishments conditional upon certain accomplishments (Bandura, 1978). Bandura asserted (1978) that the anticipated satisfactions of desired accomplishments and the dissatisfactions with insufficient ones provide incentives for actions that increase the probability of performance achievements.

\subsection{Statement of the Problem}

Praeger (2011) reports that only $12 \%$ of fourth grade Black males are proficient in reading in comparison to $38 \%$ of White males in fourth grade. Although extremely underrepresented in gifted programs and advanced classes, Black males, along with Hispanic males, constitute nearly 80 percent of youth in special education programs (Ford \& Moore, 2013; NEA, 2011; Zilanawala, et. al, 2018). The National Education Association (NEA) (2011) reveals that black males make up only nine percent of the student population in the United States, yet make up 20\% of all students classified as mentally retarded. NEA (2011) data also reveal that less than 50\% of African American male students graduate from high school on time. Losen, Hodson, Keith, Morrison, and Belway (2015) suggest that closing the achievement gap will be impossible if the discipline gap is ignored.

In a study conducted by Gregory and Weinstein (2008) at an American urban high school, they reported the enrollment distribution as 30\% African American, 37\% White, $8 \%$ Asian, 12\% Latino, 11\% mixed, and 1\% Filipino, Alaska Native, American Indian, Pacific Islander, or Native Hawaiian. Gregory and Weinstein (2008) found that although African Americans made up only $30 \%$ of the total enrollment, they constituted 58\% of students receiving office referrals for defiance related infractions. In contrast, their White counterparts produced only $5 \%$ of defiance related referrals while making up approximately 37\% of the student population (Gregory \& Weinstein, 2008). According to the National Education Association (NEA), African American males were three times more likely to receive a suspension or an expulsion from school than their White male counterparts, leading to loss of valuable instructional time in the classroom (NEA, 2011). This loss of instructional time in the classroom only further exacerbates the already gaping achievement gap between African American males and their counterparts. Lewis, Bonner, Butler, and Joubert (2010) purport that more disruption results in classroom exclusion and, subsequently, lower achievement. When students disrupt the learning process for others, student achievement is adversely impacted for all involved.

\subsection{Research Questions}

The purpose of this study was to investigate whether Positive Behavior Interventions and Support (PBIS), counseling, and mentoring had an impact on patterns of disruptive classroom behavior and reading achievement in 
African-American male students in Pre-K through fifth grade. The independent variables in this study were student participation in PBIS, counseling, and mentoring. The dependent variables were teacher reports of disruptive behaviors resulting in office referrals and student achievement in the area of reading. Quantitative research design was used to examine these variables. The sample for this study included teachers from school districts from both the northern and southern region of the state of Mississippi.

In order to investigate the variables identified in this study, the following research questions were examined:

1. Among Pre-K through fifth grade African American males, does PBIS, counseling, and mentoring have an impact on discipline referrals?

2. Among Pre-K through fifth grade African American males, does PBIS, counseling, and mentoring have an impact on reading scores?

\subsection{Hypotheses}

The following hypotheses related to the research questions were addressed in the study:

$\mathrm{H}_{1}$ There is an inverse relationship between the participation in PBIS and the number of disruptive behaviors that result in office referrals received by African American male students in Pre-K through fifth grade.

$\mathrm{H}_{2}$ There is an inverse relationship between the participation in counseling and the number of disruptive behaviors that result in office referrals received by African American male students in Pre-K through fifth grade.

$\mathrm{H}_{3}$ There is an inverse relationship between the participation in mentoring and the number of disruptive behaviors that result in office referrals received by African American male students in Pre-K through fifth grade.

$\mathrm{H}_{4}$ There is a positive relationship between the participation in PBIS and the reading scores of African American male students in Pre-K through fifth grade.

$\mathrm{H}_{5}$ There is a positive relationship between the participation in counseling and the reading scores of African American male students in Pre-K through fifth grade.

$\mathrm{H}_{6}$ There is a positive relationship between the participation in mentoring and the reading scores of African American male students in Pre-K through fifth grade.

\subsection{Review of Literature}

\subsubsection{Positive Behavior Interventions Support (PBIS)}

According to Cressey, Whitcomb, Rivet, Morrison, and Reynolds (2014), PBIS is "a prevention-oriented framework focused on creating environments that reflect safety, social competence, and healthy school climates" (pg. 91). The core of PBIS is that consistent teaching, recognizing, and rewarding of positive student behavior will reduce unnecessary discipline and promote a climate of greater productivity, safety, and learning (Fallon, O'Keeffe, Sugai, 2012). Bradshaw, Waasdorp, and Leaf (2011) proffered that PBIS changes school climate through enhanced systems, data-driven decision making, and implementation of evidenced based strategies and practices.

Sugai and Simonsen (2012) described PBIS as a Response to Intervention model (RtI) consisting of three-tiers of support and a process to solve problems that hinder schools from effectively educating all students. The primary intervention tier, Tier 1, includes supports for all students through teaching, modeling, and positively reinforcing expectations (Cressey, et al., 2014). Fairbanks, Sugai, Guardino, and Lathrop (2007) stated that more interventions are used at the secondary intervention level, Tier 2 , to produce positive outcomes for a small group of students when those students do not respond to the Tier 1 interventions. Fairbanks, et al. (2007) explained that the tertiary intervention level, Tier 3, emphasizes individualized and specialized interventions for students who are nonresponsive to Tier 1 and Tier 2 interventions. Tier 3 intervention efforts include function-based behavior intervention planning, targeting social skills instruction, intensive individualized behavior monitoring, continuous data-driven decision-making and planning teams, and school-community based mental health support (Cressey, et al., 2014). Banks and Obiakor (2015) concluded that PBIS improves school safety and climate by enhancing positive behavior for students through the implementation of the three-tiered process.

\subsubsection{Counseling}

Professional school counselors play an instrumental role in the development of students (Washington, 2010). According to the American School Counseling Association (ASCA), school counselors promote academic, career, personal, and social development of children (ASCA, 2016). Burnham and Jackson (2000) described the school counselor as an advocate for students and a leader for school and community involvement. School counselors serve 
students by identifying student issues, assessing needs, effectively using data, and initiating solutions for all students. Barna and Brott (2013) wrote that school counselors develop, implement, and evaluate comprehensive programs to assist students to achieve successful academic, social, and career development. Barna and Brott (2013) suggested that school counselors begin preparing students in elementary school through increased school engagement, improved student transitions, and equal opportunities for all students.

Rose and Steen (2014) suggested that school-based counseling programs have great potential of reaching large numbers of students. Johnson and Hannon (2014) asserted that school counselors investigate behavior and academic challenges for at-risk student populations. School counselors seek to eliminate obstacles to student success by investigating the causes of counseling referrals for disciplinary infractions for disruptive behaviors. Barna and Brott (2013) claimed interventions, especially at the elementary level, include group counseling and classroom guidance lessons that focus on personal and social growth, cooperating with others, and proper academic behavior.

\subsubsection{Mentoring}

According to Keller and Pryce (2010), the word "mentor" originated from Greek mythology. When Odysseus, King of Ithaca, left to fight in the Trojan War, he gave the responsibility of guiding and protecting his son Telemachus to a wise old man named Mentor (Holmes, Hodgson, Simari, \& Nishsimura, 2010). After the war ended, Odysseus was sentenced to wander aimlessly for ten years in his endeavor to return home. By this time, Telemachus was an adult and set out to search for his father. Athena, the Goddess of War, disguised herself as Mentor and accompanied Telemachus on his expedition (Ragins \& Kram, 2007). Thus, the word "mentor" took on the meaning of trusted guide, friend, teacher, and counselor (Holmes et. al, 2010).

As defined by Ragins and Kram (2007), the traditional meaning of mentoring is "a relationship between an older, more experienced person and a younger, less experienced protégé for the purpose of helping and developing the protégé's career" (pg. 14). According to Tindall (2009), mentoring is "a fundamental form of human development where one person invests time, energy and personal know-how in assisting the growth and ability of another person" (pg. 313). Trepanier-Street (2004) added that mentoring involves the careful and deliberate pairing of a more skilled person with a less skilled person. Although definitions may vary, the common theme is the one to one relationship between a mentor and mentee for the mentee's profit (Tolan, Henry, Schoeny, Lovegrove, \& Nichols, 2014).

\section{Methodology}

\subsection{Research Design}

The research design for this study investigating the relationship between Positive Behavior Interventions Support, counseling, and mentoring on disruptive classroom behavior and student achievement in reading of African-American male students in Pre-K through fifth grade was non-experimental and employed quantitative analyses. Data were gathered through survey method from questionnaires completed by Pre-K through fifth grade elementary school teachers. These data were analyzed using descriptive statistics, multiple regression, and logistics regression. The questionnaire focused on the outcomes of disciplinary actions received by African American males in Pre-K through fifth grade as well as their achievement scores in reading. The questionnaire also focused on the intervention strategies of PBIS, counseling, and mentoring.

\subsection{Participants}

Participants of this study included Pre-K through fifth grade elementary school teachers. Additionally, student achievement reading data and disciplinary data for students in the participating schools were also analyzed. Twenty-six public school districts in the state of Mississippi were invited to participate in this research study. However, only three school districts responded to the invitation to participate. Thus, the target sample included Pre-K through fifth grade teachers from these three school districts. It is important to note that school districts who did not employ a PBIS program would not have been included in the study. Permission was granted from three public school districts to conduct the study and to distribute the electronic questionnaires via email. The superintendents of one northern and two southern Mississippi school districts granted the researcher permission to contact teachers and conduct the study with elementary school teachers within their school districts. The instrument was distributed to 13 elementary teachers in Pre-K through fifth grade. Nine (69\%) of these teachers completed and returned the electronic questionnaire.

\subsection{Instrumentation}

The survey instrument utilized in this study consisted of three sections with a total of 35 items. Each section required participants to respond to items by selecting the correct response and also by entering the appropriate reading score 
and letter grade for the corresponding students. Section I of the instrument sought to identify the grade level taught by the teacher responding to the survey. The options offered were as follows: Pre- $K, 1^{\text {st }}, 2^{\text {nd }}, 3^{\text {rd }}, 4^{\text {th }}$ and $5^{\text {th }}$. Section II of the instrument consisted of 28 items pertaining to the variable of PBIS strategies used by teachers and received by students in the classroom. This section required teacher participants to respond to Likert-scaled items. Teacher participants responded to items addressing the use of PBIS strategies in the classroom by choosing from the following options: Never, Rarely, Sometimes, Often, or Very Often.

Section III of the instrument consisted of student information. Item 1 addressed the grade level of the student. Item 2 of Section III addressed the variable of student participation in counseling. This item requested that each participant indicate the frequency of the student's participation in counseling sessions. Items 3 and 4 of Section III consisted of items about the variable of student participation in mentoring. These items required each participant to indicate whether or not the student participated in school-based mentoring and/or community-based mentoring. Item 5 in Section III addressed the variable of disruptive behavior as measured by the number of office discipline referrals. This item requested that each participant indicate a range corresponding to how many office referrals a student had received. Participants were required to choose from the options of: $0,1-2,3$, or 4 or more. The number office referrals reported indicated whether or not the student habitually displayed disruptive behavior. Items 6 and 7 of Section III addressed the variable of student reading scores. These items asked each participant to enter a numerical and letter grade from the student's most recent report card. Participants were able to enter information for multiple students. As a result, the length of this section was determined by the number of students entered by the participants.

Responses from Items 1-28 in Section II and Items 2, 3, 4, and 5 in Section III addressed Research Question 1 and supported Hypotheses 1, 2, and 3. Responses from Items 1-28 in Section II and Items 2, 3, 4, and 6 addressed Research Question 2 and support Hypotheses 4, 5, and 6. Prior to this study, a pilot test was administered to 20 participants in order to determine reliability of the instrument. Data from the responses of pilot test participants were analyzed, and the instrument was determined to be reliable.

\subsection{Data Collection}

Upon receiving district consent and IRB approval, the purpose of the study and the data collection process was explained to the principal and/or counselor of each participating elementary school. The counselor served as the point of contact for the school site, collected consent forms, and trained teachers on the data collection process. Once the counselor returned the signed consent forms and demonstrated a clear understanding of the research study and data collection process, the research materials were provided.

A cover letter and informed consent document were provided for review by pre-K through fifth grade teachers whose participation in the study had been requested. The school counselor distributed a signed consent form to participating teachers explaining the purpose and details of the study. The form also explained that the study was voluntary and assured the participants that there would be no negative consequences for choosing not to participate in or to withdraw from the study. The letter further explained that there would be no identifiable information disclosed and that teachers' identities would remain anonymous.

The school counselors of the participating schools also distributed a letter to obtain parental consent to access student data. The letter explained the purpose and details of the study to parents of elementary African American male students. The letter also explained the study was voluntary and assured them that there would be no negative consequences for declining consent to access the data of their child. The letter also explained that the researcher would not see any identifiable information. It further explained that parents' identities would remain anonymous. The parents were informed that returning the signed parental consent letter to access student data indicated their consent to allow teachers to access their child's data.

The link to the online teacher questionnaire was emailed to the school principal and/or counselor. The school principal and/or counselor forwarded the email with the link to the participating teachers. The online teacher questionnaire consisted of Likert-type questions that required a choice for each item and one open-ended item for the reading letter grade. The teachers were asked to report his or her grade level and the frequency of the use of PBIS techniques in the classroom as classroom management mechanisms. The teacher questionnaire consisted of questions to collect the grade of the student, indicators of student participation in counseling and mentoring, number of disruptive behaviors resulting in office referrals, and reading scores and/or letter grades from the most recent grade report. This information was collected by the teacher. Identifiable information, such as names, social security numbers, MSIS numbers, and dates of birth, was not seen by the researcher or entered into the questionnaire. Once the participating teachers completed the questionnaire, he or she submitted the questionnaire electronically. There was no active participation by students in the study. 


\subsection{Data Analysis}

The responses from the questionnaire were analyzed quantitatively using descriptive statistics, multiple regression, and logistic regression analyses. Frequency, means, and standard deviations were utilized to examine teacher use of PBIS techniques in the classroom, student participation in counseling and mentoring, reading scores, and disciplinary actions resulting in office referrals. A logistic regression analysis was used to analyze Hypotheses 1, 2, and 3 to determine the relationship between the students' participation in PBIS, counseling, mentoring, and the number of disruptive behaviors that resulted in office referrals. A multiple regression analysis was used to analyze Hypotheses 4,5 , and 6 to determine the relationship between the students' participation in PBIS, counseling, mentoring, and reading scores. A significance test was also performed to determine if the research hypotheses were supported. The level of significance was set at 0.05 .

\section{Results}

\subsection{Descriptive Statistics}

Descriptive statistics were analyzed to examine teacher use of PBIS techniques in the classroom, student participation in counseling and mentoring, reading scores, and disciplinary actions resulting in office referrals. The survey consisted of three sections with a total of 35 items. Each section required participants to respond to items by choosing the correct response and entering the corresponding reading score and letter grade for each student. Section II consisted of 28 items about the variable of PBIS strategies used by teachers and received by students in the classroom. This section required teacher participants to respond to Likert-scaled items. Teacher participants responded to items addressing the use of PBIS strategies in the classroom by choosing from the options: Never, Rarely, Sometimes, Often, or Very Often.

The students in the research study received PBIS strategies used by the teacher participants in the study. Participants used PBIS strategies in their classrooms with the majority (66\%) of students receiving PBIS strategies "Often" and the remainder receiving them "Very Often". The frequencies of PBIS strategies used are listed in Table 2. Additionally, the distribution of teacher responses by grade level revealed that students receiving PBIS strategies "Very Often (34\%)" were from grades $2^{\text {nd }}$ to $5^{\text {th }}$, while there was a wider range of students receiving strategies "Often" from grades Pre-K to $5^{\text {th }}$. The distribution of responses by grade level for PBIS categories is listed in Table 3. The mean number for the variable of PBIS was $(\mathrm{M}=4.34)$. The PBIS strategy "Ignore disrupted behavior" was used less frequently among participants $(\mathrm{M}=1.4)$, while "Teach social behavior" and "Reward" were used most frequently $(\mathrm{M}=3.8$, separately). The mean and standard deviation of the variable PBIS are illustrated in Table 7.

Table 2. Frequencies of PBIS strategies

\begin{tabular}{lll}
\hline PBIS category & Frequency & Percent \\
\hline Often & 23 & $65.7 \%$ \\
Very Often & 12 & $34.3 \%$ \\
Total & 35 & $100.0 \%$ \\
\hline
\end{tabular}

Table 3. Distribution of PBIS strategies by grade level

\begin{tabular}{llllllll} 
& \multicolumn{2}{l}{ PBIS Categories } & \multicolumn{3}{l}{ Total } \\
\cline { 2 - 7 } & \multicolumn{2}{l}{ Often } & $\mathrm{n}$ & $\%$ & $\mathrm{n}$ & $\%$ \\
\hline Grade Level & $\mathrm{N}$ & $\%$ & 0 & $0.0 \%$ & 5 & $14.3 \%$ \\
\hline Pre-K & 5 & $14.3 \%$ & 0 & $0.0 \%$ & 2 & $5.7 \%$ \\
$\mathrm{~K}$ & 2 & $5.7 \%$ & 0 & $0.0 \%$ & 10 & $28.6 \%$ \\
$1^{\text {st }}$ & 10 & $28.6 \%$ & 3 & $8.6 \%$ & 5 & $14.3 \%$ \\
$2^{\text {nd }}$ & 2 & $5.7 \%$ & 4 & $11.4 \%$ & 4 & $11.4 \%$ \\
$3^{\text {rd }}$ & 0 & $0.0 \%$ & 0 & $0.0 \%$ & 4 & $11.4 \%$ \\
$4^{\text {th }}$ & 4 & $11.4 \%$ & 5 & $5.0 \%$ & 5 & $14.3 \%$ \\
$5^{\text {th }}$ & 0 & $0.0 \%$ & 12 & $34.3 \%$ & 35 & $100.0 \%$ \\
Total & 23 & $65.7 \%$ & & & & & \\
\hline
\end{tabular}


Responses from Item 2 of Section III of the questionnaire addressed the variable of student participation in counseling. This item asked each participant to indicate the frequency of the student participating in counseling sessions. Teacher participants reported that 26 students (74\%) did not participate in counseling sessions, while nine students $(26 \%)$ participated counseling sessions. The frequencies of students participating in counseling are illustrated in Table 4. Responses from items 3 and 4 of Section III of the questionnaire consisted of items about the variable of student participation in mentoring. These items asked each participant to indicate whether or not the student participated in school-based mentoring and/or community-based mentoring. Teacher participants reported that 27 students (77\%) did not have a mentor, while eight students (23\%) did have a mentor. The frequencies of students participating in mentoring are illustrated in Table 5.

Responses from Item 5 in Section III of the survey addressed the dependent variable of disruptive behavior measured by the number of office referrals. This item asked each participant to indicate a range of how many office referrals a student had received. Participants were required to choose from the options: $0,1-2,3$, or 4 or more. The number office referrals reported indicated whether or not the student displayed disruptive behavior. The dependent variable, office referrals, was dichotomous. The dependent variable was coded " 1 " if students had referrals and " 0 " if students did not have referrals. Teacher participants reported that 18 students (51\%) did not receive an office referral. Teacher responses revealed that $17(49 \%)$ received one or more office referrals. The frequencies for office referrals are listed in Table 6. Responses from Items 6 and 7 of Section III of the questionnaire addressed the variable of student reading scores. The item required each participant to enter a numerical and letter grade from the most recent report card. The mean for the variable of reading scores was $(\mathrm{M}=83.23)$. The mean and standard deviation for reading scores are illustrated in Table 7.

Table 4. Frequencies of students in counseling

\begin{tabular}{lll}
\hline Counseling & Frequency & Percent \\
\hline No & 26 & $74.3 \%$ \\
Yes & 9 & $25.7 \%$ \\
Total & 35 & $100.0 \%$ \\
\hline
\end{tabular}

Table 5. Frequencies of students in mentoring

\begin{tabular}{lll}
\hline Mentoring & Frequency & Percent \\
\hline No & 27 & $77.1 \%$ \\
Yes & 8 & $22.9 \%$ \\
Total & 35 & $100.0 \%$ \\
\hline
\end{tabular}

Table 6. Frequencies of students receiving referrals

\begin{tabular}{lll}
\hline Referrals & Frequency & Percent \\
\hline No & 18 & $51.4 \%$ \\
Yes & 17 & $48.6 \%$ \\
Total & 35 & $100.0 \%$ \\
\hline
\end{tabular}

Table 7. Descriptive statistics for PBIS and reading score

\begin{tabular}{llll}
\hline Variable & $\mathrm{n}$ & Mean & $\mathrm{SD}$ \\
\hline PBIS & 35 & 4.34 & 0.48 \\
Reading Score & 35 & 83.23 & 10.1 \\
\hline
\end{tabular}

\subsection{Research Questions and Hypotheses Results}

This study addressed two research questions and six hypotheses. Research Question 1 asked: Among Pre-K through fifth grade African American males, does PBIS, counseling, and mentoring have an impact on disciplinary referrals? Hypotheses 1, 2, and 3 were associated with Research Question 1. Research Question 2 asked: Among Pre-K 
through fifth grade African American males, does PBIS, counseling, and mentoring have an impact on reading scores? Hypotheses 4, 5, and 6 were associated with Research Question 2.

A logistic regression analysis tested Hypotheses 1, 2, and 3 to determine the relationship between the students' participation in PBIS, counseling, mentoring, and disruptive behaviors that resulted in disciplinary referrals. The independent variables were counseling, mentoring, and PBIS, and the dependent variable was office referrals. The dependent variable, office referrals, was dichotomous. The dependent variable was coded " 1 " if students had referrals and " 0 " if students did not have referrals. The sample size was $N=35$, and there were no missing cases in the data. A test of the full model including all three predictors was compared against a constant-only model. The results indicated that the full model was a significant predictor of whether or not students were referred due to disciplinary action $\left(\chi^{2}(3, N=35)=.011, p<.001\right)$. This revealed that the predictors, together, significantly distinguished between students who were referred due to disciplinary action and those that were not referred.

Furthermore, Nagelkerke $R$ Square was .363 , indicating that the model explains $36.3 \%$ of the variation in whether or not a student receives a referral. The Hosmer and Lemeshow test was not significant $\left(\chi^{2}(3)=12.51, p=.085\right)$, indicating that the model was a good fit at different observed levels of the outcome. The classification table based on a model without any predictors (constant only) correctly predicted outcomes $51.4 \%$ of the time. Adding predictors to the model, the correct prediction of outcomes increased to $74.3 \%$, with $83.3 \%$ correctly classifying no referral, and $64.7 \%$ correctly classifying a referral.

Hypothesis 1 stated: There is an inverse relationship between the participation in PBIS and the number of disruptive behaviors that result in office referrals received by African American male students in Pre-K through fifth grade. Responses from Items 1-28 in Section II and item 5 in Section III of the questionnaire addressed this hypothesis. A logistic regression analysis was used to test Hypothesis 1 to determine the relationship between the students' participation in PBIS and disruptive behaviors that result in office referrals. PBIS had an odds ratio (Exp(B)) of less than one, indicating a negative relationship with the outcome. Using the Wald statistic criteria, no significance was found for PBIS $\left(x^{2}(1, N=35)=.167, p=.682\right)$. The hypothesis was not supported. These results are listed in Table 8.

Hypothesis 2 stated: There is an inverse relationship between the participation in counseling and the number of disruptive behaviors that result in office referrals received by African American male students in Pre-K through fifth grade. Responses from Items 2 and 5 in Section III of the questionnaire addressed this hypothesis. A logistic regression analysis was used to test Hypothesis 2 to determine the relationship between the participation in counseling and disruptive behaviors that result in office referrals. Counseling had an odds ratio $(\operatorname{Exp}(\mathrm{B}))$ of less than one, indicating a negative relationship with the outcome. Using the Wald statistic criteria, the test revealed that counseling $\left(x^{2}(1, N=35)=5.375, p=.020\right)$ was the only significant predictor of disruptive behaviors that result in office referrals. The hypothesis was supported. Thus, the odds of being referred as a result of disciplinary action is 0.06 times less for a student who participated in counseling sessions compared to a student who did participate in counseling sessions. These results are listed in Table 8.

Hypothesis 3 stated: There is an inverse relationship between the participation in mentoring and the number of disruptive behaviors that result in office referrals received by African American male students in Pre-K through fifth grade. Responses from Items 3, 4, and 5 in Section III of the questionnaire addressed this hypothesis. A logistic regression analysis was used to test Hypothesis 3 to determine the relationship between the students' participation in mentoring and disruptive behaviors that result in office referrals. Mentoring had an odds ratio $(\operatorname{Exp}(\mathrm{B}))$ of less than one, indicating a negative relationship with the outcome. Using the Wald statistic criteria, no significant result was found for mentoring $\left(x^{2}(1, N=35)=2.206, p=.138\right)$. The hypothesis was not supported. These results are listed in Table 8.

Table 8. Summary of regression analysis for variables predicting disciplinary referrals

\begin{tabular}{lllllll}
\hline & $\begin{array}{l}\text { Unstandardized } \\
\text { Coefficients }\end{array}$ & Standard & & & & Exp \\
Variables & $\mathrm{B}$ & Error & Wald & $d f$ & Sig & $B$ \\
\hline Constant & 3.351 & 1.438 & 5.430 & 1 & .020 & 28.525 \\
Counseling & -2.857 & 3.806 & -0.002 & 1 & .020 & .057 \\
Mentoring & -1.489 & 1.003 & 2.206 & 1 & .138 & .226 \\
PBIS &.- .423 & 1.033 & .167 & 1 & .682 & .655 \\
\hline
\end{tabular}


Research Question 2 asked: Among Pre-K through fifth grade African American males, does PBIS, counseling, and mentoring have an impact on reading scores? Hypotheses 4, 5, and 6 were associated with Research Question 2. A multiple regression analysis was used to test Hypotheses 4, 5, and 6 to determine the relationship between the students' participation in PBIS, counseling, mentoring, and reading scores. The independent variables were counseling, mentoring, and PBIS. The dependent variable was reading scores. Additionally, PBIS was centered to help with interpretation. The sample size was $N=35$, and there were no missing cases in the data. The model summary revealed an $R^{2}$ of 0.253 indicating $25.3 \%$ of the variation in reading scores can be explained by the model containing all predictor variables. The model was statistically significant with $F(3,31)=3.496, p=0.027$. These results indicated that the model, with all the predictors included, was a good predictor of reading scores. These results are listed in Table 9.

Hypothesis 4 stated: There is a positive relationship between participation in PBIS and the reading scores of African American male students in Pre-K through fifth grade. Responses from Items 1-28 in Section II and item 6 in Section III of the questionnaire addressed this hypothesis. The test revealed a negative $\beta$ coefficient for PBIS indicating a negative relationship. No significant relationship was found for PBIS center $(\beta=-3.86, p=0.35)$. The hypothesis was not supported. These results are listed in Table 9. Hypothesis 5 stated: There is a positive relationship between participation in counseling and the reading scores of African American male students in Pre-K through fifth grade. Responses from Items 2 and 6 in Section III of the questionnaire addressed this hypothesis. The test revealed a negative $\beta$ coefficient for counseling indicating a negative relationship. No significant relationship was found for counseling $(\beta=-0.04, p=0.99)$. The hypothesis was not supported. These results are illustrated in Table 9 .

Hypothesis 6 stated: There is a positive relationship between participation in mentoring and the reading scores of African American male students in Pre-K through fifth grade. Responses from Items 3, 4, and 6 in Section III of the questionnaire addressed this hypothesis. The test revealed a negative $\beta$ coefficient for mentoring indicating a negative relationship. However, mentoring was the only significant predictor of reading scores, $\beta=-10.96, p<.001$. Looking at the beta (standardized) values, mentoring had the highest impact on predicting reading score, with $\beta=$ -0.462. These findings revealed that, holding the other variables constant, students who participated in mentoring scored lower on reading scores as compared to students who did not participate in mentoring. Since the test revealed a negative relationship with the outcome, the hypothesis was not supported. These results are listed in Table 9.

Table 9. Summary of regression analysis for variables predicting reading scores

\begin{tabular}{llllll}
\hline & $\begin{array}{l}\text { Unstandardized } \\
\text { Coefficients }\end{array}$ & $\begin{array}{l}\text { Standard } \\
\text { Error }\end{array}$ & $\begin{array}{l}\text { Standardized } \\
\text { Coefficients } \\
\text { Beta }\end{array}$ & $\mathrm{t}$ & $\mathrm{Sig}$ \\
\hline Variables & $\mathrm{B}$ & 1.969 & & 43.528 & $<.001$ \\
\hline Constant & 85.727 & 3.806 & -0.002 & -0.010 & 0.992 \\
Counseling & -0.038 & 3.723 & -0.462 & -2.943 & 0.006 \\
Mentoring & -10.958 & 4.065 & -0.158 & -0.950 & 0.349 \\
PBIS & -3.862 & & & & \\
\hline
\end{tabular}

The analysis of the data indicated that there was not a significant relationship between the participation in PBIS and the number of disruptive behaviors that result in office referrals received by African American male students in Pre-K through fifth grade. There was no significant relationship between the participation in mentoring and the number of disruptive behaviors that result in office referrals. The analysis of the data indicated that counseling was the only significant predictor of disruptive behaviors that result in office referrals. The analysis of the data indicated no significant relationship between the participation in PBIS and the reading scores of African American male students in Pre-K through fifth grade. There was no significant relationship between participation in counseling and reading scores. The analysis of the data indicated that mentoring was the only significant predictor of reading scores. However, the test revealed a negative relationship between mentoring and reading scores. Thus, the hypothesis regarding mentoring and reading scores was not supported.

\subsection{Major Findings}

Results of the analysis of Hypothesis 1 indicated that participation in PBIS was not a significant predictor of the number of disruptive behaviors that resulted in office referrals received by African American male students in Pre-K through fifth grade. Student participation in PBIS had no impact on disruptive behaviors that resulted in office 
referrals. According to the results of the analysis related to Hypothesis 2, participation in counseling was the only significant predictor of the number of disruptive behaviors that resulted in office referrals received by African American male students in Pre-K through fifth grade. Student participation in counseling did have an impact on disruptive behaviors that resulted in office referrals. The analysis of Hypothesis 3 produced results indicating that participation in mentoring was not a significant predictor of the number of disruptive behaviors that resulted in office referrals received by African American male students in Pre-K through fifth grade. Student participation in mentoring had no impact on disruptive behaviors that resulted in office referrals.

Findings from the analysis of Hypothesis 4 indicated that participation in PBIS was not a significant predictor of reading scores received by African American male students in Pre-K through fifth grade. Student participation in PBIS did not have a significant impact on reading scores. Results of the analysis of Hypothesis 5 indicated that participation in counseling was not a significant predictor of reading scores received by African American male students in Pre-K through fifth grade. Student participation in counseling did not have a significant impact on reading scores. The analysis of the data regarding Hypothesis 6 indicated that mentoring was the only significant predictor of reading scores. However, the test revealed a negative relationship between mentoring and reading scores. Thus, the hypothesis regarding mentoring and reading scores was not supported.

\subsection{Discussion}

Results of this study indicated that participation in PBIS was not a significant predictor of the number of disruptive behaviors that resulted in office referrals received by African American male students in Pre-K through fifth grade. Student participation in PBIS had no impact on disruptive behaviors that resulted in office referrals. This finding was not consistent with recent literature, which asserted that schools implementing PBIS school-wide have fewer office discipline referrals (Crump \& Lo, 2017) This finding also contradicted results from a study conducted in Louisiana by Barrett and Harris (2018) that revealed that PBIS strategies reduced the number of suspensions by 0.14-0.38 per student per year (26-72 percent from baseline) and the number of suspension days by 0.7-1.5 (at least 52 percent).

The results from this study revealed that participation in counseling was the only significant predictor of the number of disruptive behaviors that resulted in office referrals received by African American male students in Pre-K through fifth grade. Student participation in counseling had an impact on disruptive behaviors that resulted in office referrals. This finding was consistent with literature that reported that school counselors play an instrumental role in reducing disciplinary infractions (Washington, 2010; Bryan, Vines, Griffin, \& Thomas, 2011). They further assert that rates of suspensions for students of color decreased when counseling services increased.

The results from this study also indicated that participation in mentoring was not a significant predictor of the number of disruptive behaviors that resulted in office referrals received by African American male students in Pre-K through fifth grade. Student participation in mentoring had no impact on disruptive behaviors that resulted in office referrals. This finding contradicted literature that maintained that mentoring programs reduced referrals and suspensions (Schwartz, Lowe, \& Rhodes, 2012). Findings from this study conflicted with the assertion of Toms and Stuart (2014) that there is a positive relationship between mentoring and positive behavior of students who are at risk for exclusionary sanctions.

The results from this study also indicated that participation in PBIS did not significantly predict reading scores received by African American male students in Pre-K through fifth grade. Student participation in PBIS did not have a significant impact on reading scores. This finding differed from the findings on the impact of PBIS given by the Office of Special Education Programs National Technical Assistance Center (OSEP). OSEP (2018) maintains that implementation of PBIS strategies yield "improvements in academic engagement and achievement" (pg. 1). This finding also contradicted results from a study that revealed that student outcomes were significantly higher at schools implementing PBIS with fidelity (Houchens, Zhang, Davis, Niu, Chon, \& Miller, 2017).

The results from this study revealed that participation in counseling was not a significant predictor of reading scores among African American male students in Pre-K through fifth grade. These finding were inconsistent with literature that stated that reading proficiency improved when students of color participated in counseling programs (Bell, 2010). The findings of this study were also inconsistent with the findings of Lopez and Mason (2018) which found that participation in counseling had a positive impact on student achievement. The results from this study also revealed that mentoring was the only significant predictor of reading scores. However, the test revealed a negative relationship between mentoring and reading scores. Thus, the hypothesis regarding mentoring and reading scores was not supported. These findings were inconsistent with the literature that posited that mentoring programs improved the academic performance (Schwartz, et. al, 2012). The findings of this study also opposed the stance of Dickerson and Agosto (2015) that mentoring positively impacts academics of youth from all types of backgrounds. 


\subsection{Limitations}

The results of this study contained limitations that could potentially impact the generalizability of the results presented herein. Although the results of the study did not indicate significance with regard to the impact of PBIS and mentoring on the behavior of African American elementary age male students nor reading achievement scores, it should be noted that the sample size for this study was very low. It should also be noted that although the results this study pointed to significance with regard to the impact of counseling on the behavior of African American elementary age male students, the limited sample size could also be a factor in the interpretation of the results. Although the researchers sought to examine a representative sample of schools with active PBIS Programs in place from throughout the state, the response rate from the superintendents granting approval to conduct the study in their districts was less than ideal. Therefore, the limited number of districts granting approval significantly impacted access to the number of schools which limited access to the number of teachers participating. It is intended that the researchers will revisit this study by expanding the sample population beyond one state to increase the overall participation in the study.

\section{References}

American School Counseling Association. (2016). Legislative Affairs. Retrieved from https://www.schoolcounselor.org/school-counselors-members/legislative-affairs

Bandura, A. (1969). Handbook of Socialization Theory and Research. New York: Rand McNally and Company.

Bandura, A. (1971). Social Learning Theory. General Learning Press.

Bandura, A. (1977). Social Learning Theory. General Learning Press.

Bandura, A. (1978). The self system in reciprocal determinism. American Psychologist, 33(4), 344-358.

Bandura, A. (2001). Social cognitive theory: an agentic perspective. Annual Review of Psychology, 52, 1-26.

Banks, T., \& Obiakor, F. (2015). Culturally responsive positive behavior supports: considerations for practice. Journal of Education and Training Studies, 3(2), 84-90.

Barna, J., \& Brott, P. (2013). Making the grade: the importance of academic enablers in the elementary school counseling program. Professional School Counseling, 17(1), 97-110.

Barrett, N., \& Harris, D. (2018). The effects of a positive behavior interventions and supports (PBIS) data platform on student academic and disciplinary outcomes. Education Research Alliance for New Orleans, 1-50. Retrieved from https://educationresearchalliancenola.org/files/publications/Barrett-Harris-Technical-Report-Final.pdf

Bell, E. (2010). Educating African American males. Understanding Black Males, 1-20. Retrieved from http://files.eric.ed.gov/fulltext/ED514552.pdf

Bracy, N., \& Peguero, A. (2014). School order, justice, and education: climate, discipline practices, and dropping out. Journal of Research on Adolescence, 25(3), 412-426.

Bradshaw, C., Waasdorp, T., \& Leaf, P. (2015). Examining variation in the impact of school-wide positive behavioral interventions and supports: findings from a randomized controlled effectiveness trial. Journal of Education Psychology, 107(2), 46-587.

Bryan, J., Vines, N., Griffin, D., \& Thomas, C. (2011). The disproportionality dilemma: patterns of teacher referrals to school counselors for disruptive behavior. Journal of Counseling and Development, 90, 177-190.

Burchinal, M., McCartney, K., Steinberg, L., Crosnoe, R., Friedman, S., McLoyd, M., \& Picanta, R. (2011). Examining the black-white achievement gap among low-income children using the NICHD study of early child care and youth development. Child Development, 82(5), 1404-1420.

Burnham, J., \& Jackson, M. (2000). School counselor roles: discrepancies between actual practice and existing models. Professional School Counseling, 4(1), 41.

Cressey, J., Whitcomb, S., Rivet, S., Morrison, R., \& Reynolds, K. (2014). Handling PBIS with care: scaling up to school-wide implementation. Professional School Counseling, 18(1), 90-99.

Crump, K., \& Lo, Y. (2017). An investigation of multi-tiered behavioral interventions on disruptive behavior and academic engagement of elementary students. Journal of Positive Behavior Interventions, 19(4), 216-217.

Dickerson, S., \& Agosto, V. (2015). Revising curriculum to mentor young black men. Curriculum \& Teaching Dialogue, 17(1,2), 85-101. 
Fairbanks, S., Guardino, D., \& Lathrop, M. (2007). Response to intervention: examining classroom behavior in second grade. Exceptional Children, 73(3), 288-310.

Fallon, L., O'Keeffe, B., \& Sugai, G. (2012) .Consideration of culture and context in school-wide positive behavior support: a review of current literature. Journal of Positive Behavior Interventions, 14(4), 209-219.

Ford, D., \& Moore, J. (2013). Understanding and reversing underachievement, low achievement, and achievement gaps among high-ability African American males in urban school contexts. Urban Review, 45, 399-415.

Gregory, A., \& Weinstein, R. (2008). The discipline gap and African Americans: defiance or cooperation in the high school classroom. Journal of School Psychology, 46(4), 455-75.

Gregory, A., Skiba, R., \& Noguera, P. (2010). The achievement gap and the discipline gap: two sides of the same coin. Educational Researcher, 39(1), 59-68.

Holmes, D., Hodsgon, P., Simari, R., \& Nishimura, R. (2010). Mentoring: making the transition from mentee to mentor. Circulation, 336-340.

Houchens, G., Zhang, J., Davis, K., Niu, C., Chon, K., \& Miller, S. (2017). The impact of positive behavior interventions and supports on teachers' perceptions of teaching conditions and student achievement. Journal of Positive Behavior Interventions, 19(3), 168-179.

Johnson, K., \& Hannon, M. (2014). Measuring the relationship between parent, teacher, and student problem behavior reports and academic achievement: implications for school counselors. Professional School Counseling, 18(1), 38-48.

Keller, T., \& Pryce, K. (2010). Mutual but unequal: mentoring as a hybrid of familiar relationship roles. New Directions for Youth Development, 2010(126), 33-50.

Lewis, W., Butler, B., Bonner, F., \& Joubert, M. (2010). African American male discipline patterns and school district responses resulting impact on academic achievement: implications for urban educators and policy makers. Journal of African American Males in Education, 1(1), 1-25.

Lopez, C., \& Mason, E. (2018). School counselors as curricular leaders: A content analysis of ASCA Lesson Plans. Retrieved from https://journals.sagepub.com/doi/full/10.1177/2156759X18773277

Losen, D., Hodson, C., Keith, M., Morrison, K., \& Belway, S. (2015). Are we closing the school discipline gap?. The Civil Rights Project. Retrieved from https://www.civilrightsproject.ucla.edu/resources/projects/center-for-civil-rights-remedies/school-to-prison-fold er/federal-reports/are-we-closing-the-school-discipline-gap

National Education Association. (2011). Race against time: educating black boys. Focus On, 1-8.

Office of Special Education Programs National Technical Assistance Center on PBIS. (2018). Brief introduction and frequently asked questions about PBIS. Retrieved from https://www.pbis.org/Common/Cms/files/pbisresources/What\%20is\%20PBIS\%20Q\&A\%2030\%20June\%2020 18.pdf

Praeger, K. (2011). Positioning young black boys for educational success. Policy Evaluation and Research Center, 19(3), 1-15.

Ragins, K., \& Kram, K. (2007). The Handbook of Mentoring at Work: Theory, Research, and Practice. Retrieved from

https://play.google.com/books/reader?id=IWRECgAAQBAJ\&printsec=frontcover\&output=reader\&hl=en_US\& pg=GBS.PT3

Richard, L., \& Hardin, L. (2018). Suspensions and special education: an examination of disproportionate practices. National Teacher Education Journal, 11(2), 67-74.

Rose, J., \& Steen, S. (2014). The achieving success everyday group counseling model: fostering resiliency in middle school students. Professional School Counseling, 18(1), 28-37.

Rudd, T. (2014). Racial disproportionality in school discipline. Kirwan Institute Issue Brief. Retrieved from http://kirwaninstitute.osu.edu/wp-content/uploads/2014/02/racial-disproportionality-schools-02.pdf

Schwartz, S., Lowe, S., \& Rhodes, J. (2012). Mentoring relationships and adolescent self-esteem. The Prevention Researcher, 19(2), 17-20. 
Sugai, G., \& Simonsen, B. (2012). Positive behavioral interventions and supports: history, defining features, and misconceptions. Retrieved from https://www.pbis.org/school/pbis_revisited.aspx

Tindall, J. (2009). Peer helping through mentoring (3rd ed.). Workbook Applying Peer Helper Skills.

Tolan, P., Henry, D., Schoeny, M., Lovegrove, P., \& Nichols, E. (2014). Mentoring programs to affect delinquency and associated outcomes of youth at risk: a comprehensive meta-analytic review. Journal of Experimental Criminology, 10, 179-206.

Toms, M., \& Stuart, S. (2014). Mentoring strategies for decreasing suspensions of students with behavioral disorders. Journal of Emerging Trends in Educational Research and Policy Studies, 5(7), 6-11.

Trepanier-Street, M. (2004). Teachers: mentors of children. Childhood Education, 81(2), 66-69.

Washington, A. (2010). Professional school counselors and African American males: using school/community collaboration to enhance academic performance. Journal of African American Males in Education, 1(1), 26-39.

Zilanawala, A., Martin, M., Noguera, P., \& Mincy, R. (2018). Math achievement trajectories among black male students in the elementary and middle school years. Educational Studies, 54(2), 143-164. 